\title{
Research on Users' Behaviors in Virtual Communities From the Perspective of Information Ecology
}

\author{
Yi Peng ${ }^{1}$, Jing Chen ${ }^{2 *}$ and $\mathrm{Yi}_{\mathrm{Li}^{3}}$ \\ School of Economics and Management, Chongqing University of Posts and \\ Telecommunications, Chongqing 400065, China \\ 1635644882@qq.com, ${ }^{2}$ chenjing@cqupt.edu.cn, ${ }^{3}$ yili.cqupt@gmail.com
}

\begin{abstract}
Based on the theory of information ecology, this paper explores the factors influencing two behaviors, interaction participation and information adoption, of users in virtual communities by combining three core elements in information ecology: information, information man and information environment. Using data collected from 401 users in virtual communities to conduct a hypothesis testing, the empirical results show that 1) Usefulness, trust and security have direct positive effects on interaction participation; 2) usefulness has a direct positive effect on information adoption; 3) interaction of trust and security has a positive effect on information adoption.
\end{abstract}

Keywords: interaction participation; information adoption; virtual communities; information ecology

\section{Introduction}

The virtual community is online social networks where people, who have common interests, goals, or practices, interact to share information and knowledge, and engage in the social interaction [1]. With the advance of information technology, the virtual communities have been developed rapidly, which have made different forms of virtual communities appear in the networks, such as Baidu Post Bar, Tianya Community, Zhihu, Douban, and so forth. The virtual communities have become important platforms for information flowing and sharing, and they can enhance the social contact of users [1], realize users' self-efficacy [2], and meet the needs of users for getting information [3]. In the information age today, users need such platforms for their interaction participation and information adoption.

Interaction participation can be understood as such two parts as "interaction" and "participation". Interaction means 'being in contact' with two or more partners regardless of the activities that attract them together [4]. Community members interact on a regular basis online and have the exchange in order to form a mutual relationship [4]. Participation means that voluntary and members can share no prior organizational affiliation [4]. Participation in communities has been regarded as a measurement of the community's gain because it displays member satisfaction while at the same time promoting important community goals [5]. Interaction participation can enhance information exchange activities so as to enhance information exchange and information sharing among users, which plays an important role to virtual communities.

Information adoption is a process in which people can purposefully utilize information [6]. It connects information pursuit, information choice, information search and information utility, which makes each part of artificially differentiated information behavior more complete and reasonable; in the name of its concept it

${ }^{*}$ Corresponding Author 
reflects characteristics of integrity, relevance and structure among each components of information behavior [7]. Behavior of information adoption in this paper refers to a behavior of information absorption and utilization after activities, such as information pursuit, choices, analysis, assessment, and so forth, are conducted in virtual communities. Information adoption behavior is a kind of the principal activities that the user intends to conduct in the virtual community [6]. It can promote the development of virtual communities, accelerate the speed of information transmission, and have a positive effect on users as well.

Interaction participation and information adoption are two important behaviors in virtual communities in their mutual promotion and their mutual action. Interaction participation is a way to get information source, to search information, and to assess information; information adoption is a driving force to exchange information, to share information and to establish social connections, In the human-centered virtual communities, users' interaction participation and information adoption is a way to meet their needs and to realize their values, and a core in the virtual communities as well. However, influencing factors on interaction participation and information adoption need further exploring. Therefore, the research of this paper is of important theoretic and practical significance.

\section{Literature Review}

Currently, studies, including interaction participation and information adoption, are uncommon. As for studies on the interaction participation, Yoo et. al., explored the factors that enhance member participation in business-to-customer virtual communities [5]; Yang et. al., distinguished active and passive social interactions in the learning community with a conceptual framework [8]; Shen et. al., investigated virtual community loyalty from the perspective of interpersonal interaction among group members, treating interpersonal attraction and influence as antecedents to loyalty [9]. As for studies on information adoption, Ronnie has discussed the information adoption act of the users on EWOM, and investigated how it affects users' purchase intention [10]; An and Mark have established a social framework to study the adoption of online news, information adoption, and information use [11]; Lee and Yang have analyzed information adoption act on the basis of the online product evaluation from new product developers [12].

Most previous studies only focus on interactive participation and information adoption respectively, lacking researches containing both the two acts on the users' behavior in virtual community. However, interaction participation and information adoption are main acts in virtual communities, and have an important impact and value on their users. In addition, since the two are formed under the same situation, they are both affected by common virtual community information, individuals and the environment. Therefore, it is necessary to combine the two acts in study. In terms of researching variety, researchers rarely analyze users' acts by applying a main effect and an interaction effect in literatures. In the virtual community, it is likely existing links among factors of user acts, whose factors could have an impact on users' acts. Therefore, a comprehensive discussion requires a combination of main and interaction effects of users' acts.

Different from the existing literature, research work includes: 1. Regarding a virtual community as a situation, this paper gives a clear explanation of the two behaviors, interaction participation and information adoption. 2. Based on the information ecology theory, starting from the three elements, that is, information, information man and information environment, the factors influencing -the users' behaviors in the virtual community are discussed. 3 . Combining with the main effect 
and the interaction effect, this paper analyzes users' behaviors, and establishes a research model from the perspective of information ecology at last.

\section{Background}

Information ecology is used to express the contact between an ecological concept and information environment [13]. Because the information environment is becoming increasingly important and complex today, information ecology owns a significant value for existence. In 1999, Nardi and O'Day defined information ecology as a system composed of people, practices, values and technology in a certain environment [14]. They discussed the relationship between IT and human beings in a certain environment, and noted that a human activity served by the technology is more important than technology itself [15]. Other scholars believe that information is the sum of the ecological factors and their relationships to each other within a certain range of information resources [16], the sum of the relationship between information, people, the environment [17], and an integrity formed by the process of communication and circulation for information between people, organizations, and communities in a certain space [18]. Analyzing from the systematic perspective, information ecosystem is composed of information, information man and information environment, which are key elements forming ecosystem [19], of which, information is an object of ecology, information man is a subject, and the information environment is not only an ecological background and place, but also the sum of all external factors related to the information [20].

This paper argues that, under the information ecology theory, information, information man, and information environment are correlated and balanced. On one hand, information environment affects and restricts the information man, and play an important role in their activities and the development of their relation; on the other hand, information man feelings and cognitions of information are critical to its quality and value.

\section{Hypotheses}

\subsection{Information}

From the angle of information elements, this paper emphasizes the usefulness of information. The usefulness means the integrity and accuracy of information, which can be exploited by users, and produces good results. The usefulness, reflecting the value of information [21], is a primary factor to attract and retain users. Useful information can allow users to perceive the value of information, more willingly to exchange information, so as to improve the frequency and intensity of their interaction participation. At the same time, useful information may bring benefits to users, thus it can stimulate users' desires to adopt information, and has become a main motive of users' information adoption. Therefore, this paper puts forward the following hypotheses:

H1: The usefulness has a positive effect on interaction participation.

$\mathrm{H} 2$ : The usefulness has a positive effect on information adoption.

\subsection{Information Man}

Information man in this paper refers to the users in virtual communities. From the angle of information man, trust among information men is emphasized. Trust, reflecting users' comprehensive evaluation to another one's behavior and ability, can usually be regarded as a decision-support tool, used for the analysis of relevantly reliable information sources, especially from a reliable source to seek 
advices and make decisions [22-23]. In a virtual community centered with people, behaviors and activities of users are built on the basis of trust. On one hand, trust, a basic factor, affects interaction participation of users. The higher degree of trust there is between users, the more they are willing to communicate and share information, thus strengthening the interaction participation between them. On the other hand, trust is an important condition of information adoption. Information will appear more credible when a user believes that other users won't send false information, and may bring his help. In this way, users will hold a clearer attitude toward information adoption. Therefore, this paper proposes the following hypotheses:

H3: Trust has a positive effect on interaction participation.

H4: Trust has a positive effect on information adoption.

\subsection{Information Environment}

As for information environment, this paper emphasizes the security of information environment. Security, including network security, information security and users security, means users' privacy and sensitive content in the virtual community are under protection, and are away from various internal and external dangers, threats, harming and misleading [24]. The security of information environment is a basic guarantee of interaction participation and information adoption. In the process of interaction participation, users need to get protection in privacy, information, and systems. Interaction between users will not be effective and smooth if people fail to realize the above. In addition, information adoption is also affected by the security of a virtual community. The safety of the virtual community can reduce the possibility of the occurrence of risks, so that users can adopt more accurate and complete information to promote the production of information adoption. Therefore, the following hypotheses are presented in this paper:

H5: Security has a positive effect on interaction participation.

H6: Security has a positive effect on information adoption.

\subsection{Interaction Effect}

The usefulness of information and the trust of the information man may have interaction effects. Useful information can give users a good result which can strengthen users' trust to other users' qualities and abilities, and improve the trust between each other. Meanwhile, the trust among users can encourage them to share high quality information, thereby enhancing the value of the information, and improving the usefulness of information. The mutual combination of information usefulness and users' trust stimulates their interaction participation and information adoption. As a result, this paper raises the following hypotheses:

H7: The interaction of usefulness and trust has a positive effect on interaction participation.

H8: The interaction of usefulness and trust has a positive effect on information adoption.

Interaction effect may exist in the usefulness of information and the security of information environment. On one hand, the usefulness decreases the distortion and incompleteness of information, reduces information risks, and further improves the security of information environment. On the other hand, a safe information environment can ensure information security, and avoid information asymmetry, information pollution, and so forth, thus making it available for more useful information. The combination of information availability and security of the information environment provides a more powerful support for the users' interaction 
participation and information adoption behaviors. Therefore, the following hypotheses are made in this paper:

H9: The interaction of usefulness and security has a positive effect on interaction participation.

H10: The interaction of usefulness and security has a positive effect on information adoption.

There may be an interaction between the trust of information man and the security of information environment. Trust, as a kind of internal cognitive capability, helps reduce internal risks in the form of misunderstanding, fraud and infringement among users, so as to lower the possibility of external risks and to improve the security of information environment. At the same time, a secured information environment serves to resist external risks caused by misunderstanding, infringement, threats and other similar forms, so that the relationship among users is under protection and the degree of trust among them is accordingly improved. It will be better to promote both users' interaction participation and their behaviors in information adoption if the trust of the information man and the security of information environment are combined. Therefore, the following hypotheses are made in this paper:

H11: The interaction of trust and security has a positive effect on interaction participation.

H12: The interaction of trust and security has a positive effect on information adoption.

\section{Methods}

\subsection{Measurement of Variables}

As for information factors, the usefulness scale refers to the study of Ronnie [10]. In terms of the factors of the information man, its trust scale refers to the study of Gefen et. al., [25], Luo [26] and Chao et. al., [1]. When it comes to factors of information environment, its security scale refers to the study of Wang [27]. And interaction participation scale partly refers to the study of Lu [28], with the other part based on the theory of Fan [29]. Information adoption scale is worked out by revising the combination of Song's [30] scale and the situation of the virtual community. All of the above are Likert-type scale (1 indicates conformity and 5 indicates non-conformity). In addition, the respondents' genders, ages, educational levels, occupations, common names used in the virtual community, and their experiences, frequencies and other background information about the virtual community are also included in a questionnaire.

The first draft of the questionnaire has been repeatedly discussed by members of a research team, and after they take advices from related experts, a revised version is used for the formal study on a large sample.

\subsection{Sample}

In this study, samples are bought from a professional online survey firm. The advantage of an online survey is that its anonymity helps to reduce social assessment bias. A company sets up a sample library composed of more than 2.6 million people, of which 2,580 people are selected randomly by the computer to distribute questionnaires (via e-mail, etc.,). At the beginning of the questionnaire, items are designed for the selection of the virtual community users. 449 questionnaires are returned (the return rate is $17.40 \%$ ) after a rejection of invalid questionnaires (such as insufficiency in answer time, wrong keys in a trap question, obvious regularities in final answer, low frequencies in using a virtual community), 
and eventually 401 valid questionnaires are collected (validity rate is $89.31 \%$ ). Of them, 195 men account for $38.63 \%$, and 206 women hold $51.37 \%$. In terms of age structure, there are 40 people in the age group of $19-25$, accounting for $9.98 \% ; 285$ people in the group of $26-35$, accounting for $71.07 \%$; 68 people in the group of 3645 , accounting for $16.96 \%$, and 8 people are above 45 , accounting for $2.00 \%$. As for educational level, 34 people are below bachelor-degree level, accounting for $8.48 \%$, 311 people have bachelor degrees, accounting for $77.56 \%$, and 56 people hold master degrees or above, accounting for $13.97 \%$. As for profession, 74 people are relevant to the education and scientific research, accounting for $18.45 \% ; 278$ people are employees of companies, accounting for $69.33 \%$, and 49 people are in other careers, accounting for $12.22 \%$. Among all popular virtual communities, the usage rates of Baidu Tieba and Weibo are relatively high: $79.05 \%$ and $77.81 \%$ respectively. The usage rates of other common virtual communities including QQCLUB, Tianya Community, Douban and Zhihu are 47.88\%, 46.63\%, 36.91\%, and $34.41 \%$ respectively. And $93.02 \%$ of people have more than one year of experience in using virtual communities. As for the usage frequency, most people use them once a day, with a percentage of $52.37 \%$.

\section{Results}

\subsection{Reliability and Validity}

Cronbach's $\alpha$ coefficient of the five variables (serviceability, reliance, security, interaction participation and information adoption) can be calculated through SPSS 22.0, as shown in Table 1, where we can find that all of Cronbach's $\alpha$ coefficients are greater than 0.6. Hair, et. al., [31] points out that when the measure indices of variable are less than 6 , the scale is reliable on the premise of $\alpha>0.6$ while it is acceptable in exploratory researches even if $\alpha>0.5$. Therefore, the scale is equipped with relatively satisfying internal consistency reliability. Confirmatory Factor Analysis (CFA) can be conducted to the aforementioned five variables through LISREL 8.70. The model has better fitting degrees $\left(\chi^{2}=289.808, \mathrm{df}=94, \chi^{2} / \mathrm{df}=3.083\right.$, RMSEA $=0.072$, NNFI=0.957, CFI=0.967, IFI=0.967, GFI=0.917, AGFI=0.880). The loading of a normalization factor under the item falls between 0.564 and 0.767 , reaching a relatively high significant level $(\mathrm{p}<0.01)$, and showing good convergent validity. Correlation coefficients of each factor resulted from adding and subtracting standard error for two times (namely $95 \%$ of reliability interval of correlation coefficient) don't include 1 or -1 , which shows a good divergent validity. The data analysis and CFA on variables are shown as Table 1.

Table 1. Reliability Analysis and CFA

\begin{tabular}{|c|c|c|c|c|}
\hline Variables & Item Contents & $\begin{array}{c}\text { Sd. } \\
\text { Factor } \\
\text { Loading }\end{array}$ & $\begin{array}{c}\mathrm{t} \\
\text { value }\end{array}$ & $\alpha$ \\
\hline \multirow{3}{*}{ Usefulness } & Community information is basically applicable. & $.591 * *$ & 11.810 & \multirow{3}{*}{.618} \\
\hline & $\begin{array}{l}\text { The majority of community information is beneficial } \\
\text { for you. }\end{array}$ & $.641 * *$ & 12.919 & \\
\hline & Community information is helpful. & $.565^{* *}$ & 11.216 & \\
\hline Trust & $\begin{array}{l}\text { Users in the community won't send fake messages for } \\
\text { cheating purpose. }\end{array}$ & $.699 * *$ & 14.881 & .701 \\
\hline
\end{tabular}




\begin{tabular}{|c|c|c|c|c|}
\hline & $\begin{array}{l}\text { Users in the community can consider issues from } \\
\text { others' perspectives. }\end{array}$ & $.717 * *$ & 15.373 & \\
\hline & Users in the community can help others sincerely. & $.594 * *$ & 12.206 & \\
\hline \multirow{3}{*}{ Security } & $\begin{array}{l}\text { The community can protect your personal information } \\
\text { without leakage on purpose. }\end{array}$ & $.669 * *$ & 13.933 & \multirow{3}{*}{.765} \\
\hline & $\begin{array}{l}\text { You believe that there is no stealing or cheating in the } \\
\text { community. }\end{array}$ & $.763 * *$ & 16.488 & \\
\hline & $\begin{array}{l}\text { You believe that linkages in the community are safe, } \\
\text { and never worry about virus. }\end{array}$ & $.744 * *$ & 15.951 & \\
\hline \multirow{4}{*}{$\begin{array}{l}\text { Interaction } \\
\text { Participation }\end{array}$} & $\begin{array}{l}\text { You can actively respond to other users in the } \\
\text { community. }\end{array}$ & $.662 * *$ & 12.691 & \multirow{4}{*}{.695} \\
\hline & $\begin{array}{l}\text { The topics you propose can gain other users' active } \\
\text { respond. }\end{array}$ & $.569 * *$ & 11.411 & \\
\hline & $\begin{array}{l}\text { You always participate in the discussion, evaluation, } \\
\text { and activities in the community. }\end{array}$ & $.575^{* *}$ & 11.559 & \\
\hline & $\begin{array}{l}\text { You will choose to join in some organizations in the } \\
\text { community. }\end{array}$ & $.648 * *$ & 13.331 & \\
\hline \multirow{3}{*}{$\begin{array}{l}\text { Information } \\
\text { Adoption }\end{array}$} & $\begin{array}{l}\text { You will make use of the community information to } \\
\text { meet the requirements in life, study and work. }\end{array}$ & $.583 * *$ & 11.537 & \multirow{3}{*}{.672} \\
\hline & $\begin{array}{l}\text { You will initially use community information in life, } \\
\text { study and work. }\end{array}$ & $.659 * *$ & 13.303 & \\
\hline & $\begin{array}{l}\text { You always use community information in life, study } \\
\text { and work. }\end{array}$ & $.668 * *$ & 13.518 & \\
\hline
\end{tabular}
Notes: ${ }^{* *}$ refers to $\mathrm{P}<0.01$.

Besides, there exists significant difference $\left(\Delta \chi^{2}(\Delta \mathrm{df})=609.054(10), \mathrm{p}<0.01\right)$ between an imitative effect of Harman single-factor model $\left(\chi^{2}=898.862, \mathrm{df}=104\right.$, $\chi^{2} / \mathrm{df}=8.643, \mathrm{RMSEA}=0.138, \mathrm{NNFI}=0.893, \mathrm{CFI}=0.908, \mathrm{IFI}=0.908, \mathrm{GFI}=0.781$, AGFI=0.713) and an imitative effect of a five-factor model, which implies that one latent variable cannot account for all factors. Therefore, the common variance is not such a serious error. In addition, variance inflation factors (VIF) of each variable in all of the models are far less than 10, which imply that there is no serious multicollinearity among variables and the analysis result is reliable. As shown in Table 2, are mean values, standard deviations and correlation coefficients of variables.

Table 2. Mean, Standard Deviation and Correlation

\begin{tabular}{cccccc}
\hline Variables & 1 & 2 & 3 & 4 & 5 \\
\hline $\begin{array}{c}\text { 1. Information } \\
\text { Adoption }\end{array}$ & 1 & & & & \\
\hline $\begin{array}{c}\text { 2. Interaction } \\
\text { Participation }\end{array}$ & $.629^{* *}$ & 1 & & & \\
\hline 3. Usefulness & $.595^{* *}$ & $.582^{* *}$ & 1 & & \\
\hline 4. Trust & $.377^{* *}$ & $.539^{* *}$ & $.577^{* *}$ & 1 & \\
\hline 5. Security & $.259^{* *}$ & $.461^{* *}$ & $.400^{* *}$ & $.678^{* *}$ & 1 \\
\hline Mean Value & 4.027 & 3.953 & 3.910 & 3.497 & 3.395 \\
\hline Standard & .568 & .551 & .583 & .692 & .774 \\
\hline
\end{tabular}


Deviation

Notes: The sample content is 401 ; ${ }^{*}$ refers to $p<0.05$, and ${ }^{* *}$ refers to $p<0.01$, hereinafter inclusive.

\subsection{Hypothesis Testing}

6.2.1. Main Effect: Usefulness has a positive impact on interaction participation $(\beta=0.376, p<0.01)$, as well as information adoption $(\beta=0.528, p<0.01)$. Trust has a positive impact on interaction participation $(\beta=0.201, \mathrm{p}<0.01)$, while it has a nonsignificant impact on information adoption behavior $(\beta=0.528, p>0.05)$. Security has a positive impact on interaction participation $(\beta=0.184, \mathrm{p}<0.01)$, while it has a nonsignificant impact on information adoption behavior $(\beta=0.528, \mathrm{p}>0.05)$. H1, H2, H3, H5 are supported, while $\mathrm{H} 4$ and H6are not.

6.2.2. Interaction Effect: The interaction of usefulness and trust has a nonsignificant impact on interaction participation $(\beta=-0.003, p>0.05)$ as well as information adoption behavior $(\beta=-0.065, p>0.05)$. The interaction of usefulness and security has a non-significant impact on interaction participation $(\beta=-0.024, p>0.05)$ as well as information adoption behavior $(\beta=0.068, \mathrm{p}>0.05)$. The interaction of trust and security has a non-significant impact on interaction participation $(\beta=-0.035$, $p>0.05)$, while it has a positive impact on information adoption behavior $(\beta=0.114$ , p<0.05). Only $\mathrm{H} 12$ is supported, H7, H8, H9, H10, and $\mathrm{H} 11$ are not. Table 3 , is about the hypothesis testing, and the results are shown in Figure 1.

\section{Table 3. Hypothesis Testing}

\begin{tabular}{|c|c|c|c|c|c|c|}
\hline \multirow{3}{*}{ Variables } & \multicolumn{3}{|c|}{$\begin{array}{l}\text { Dependent Variable: } \\
\text { Interaction Participation }\end{array}$} & \multicolumn{3}{|c|}{$\begin{array}{l}\text { Dependent Variable: } \\
\text { Information Adoption }\end{array}$} \\
\hline & Model 1 & Model 2 & Model 3 & Model 4 & Model 5 & Model 6 \\
\hline & \multicolumn{6}{|c|}{$c_{0}$} \\
\hline Age & -.048 & .005 & .003 & -.046 & .017 & .017 \\
\hline Bachelor Bellow & -.037 & -.023 & -.020 & -.172 & -.167 & -.174 \\
\hline Master or Above & -.012 & -.025 & -.024 & -.072 & -.059 & -.063 \\
\hline $\begin{array}{c}\text { Education and } \\
\text { Research Development }\end{array}$ & -.058 & -.063 & -.063 & -.050 & -.031 & -.032 \\
\hline $\begin{array}{c}\text { Institutional and Other } \\
\text { Organizations }\end{array}$ & .054 & -.014 & -.014 & .096 & .042 & .031 \\
\hline Usefulness & & .398 & .376 & & .555 & .528 \\
\hline Trust & & .192 & .201 & & .064 & .037 \\
\hline Security & & .179 & .184 & & -.013 & .042 \\
\hline Usefulness $\times$ Trust & & & -.035 & & & -.065 \\
\hline Usefulness $\times$ Security & & & -.024 & & & .068 \\
\hline Trust $\times$ Security & & & -.003 & & & .114 \\
\hline $\mathrm{R}^{2}$ & .011 & .422 & .424 & .048 & .387 & .407 \\
\hline $\mathrm{F}$ & .861 & $35.741^{* *}$ & $26.053^{* *}$ & $4.012^{* * *}$ & $30.906^{* *}$ & $24.252^{* *}$ \\
\hline$\Delta \mathrm{R}^{2}$ & .011 & .411 & .002 & .048 & .338 & .020 \\
\hline $\mathrm{F}$ of $\Delta \mathrm{R}^{2}$ & .861 & $92.874^{* *}$ & .548 & $4.012^{* *}$ & $72.117^{* *}$ & $4.379^{* *}$ \\
\hline Maximum VIF Value & 1.058 & 2.347 & 2.460 & 1.058 & 2.347 & 2.460 \\
\hline
\end{tabular}




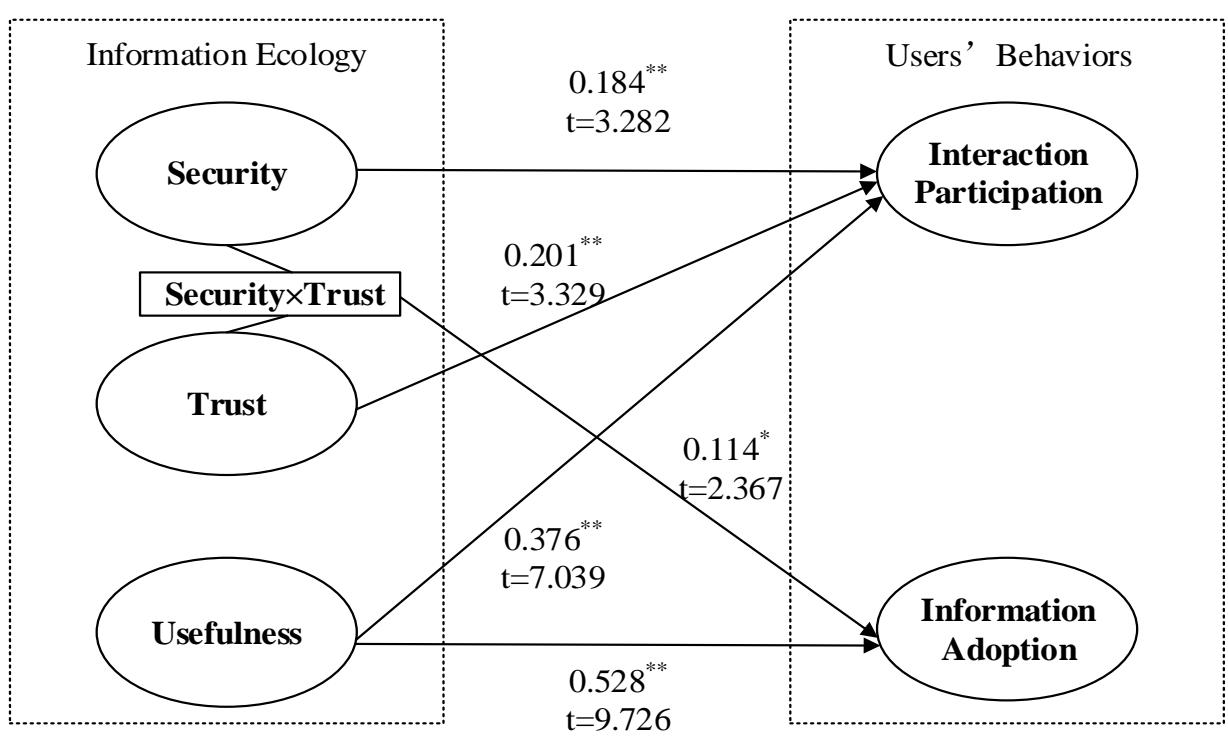

Figure 1. Research Results

\section{Conclusion}

Based on the information ecology theory, this paper constructs the user behavior model in virtual communities. Using data collected through a survey of 401 users in virtual communities, we empirically test the hypothesis. The main conclusions are as follows: firstly, usefulness, trust and security have positive impact directly on interaction participation. Secondly, three interactions (usefulness and trust; usefulness and security; trust and security) show no significant impacts on interaction participation. This illustrates that the interaction effect among factors are weakly concerning interaction participation, which makes the hypotheses not be supported. Thirdly, usefulness has a positive impact directly on information adoption, while trust and security show no significant impacts on it. The reason may be that the value of information adoption mainly reflect in the value of its information, while trust and security only influence the trust and safety of the information rather than directly embody the value of the information. Fourthly, the interaction of trust and security has a positive influence on information adoption while the rest two interactions (usefulness and trust; usefulness and security) have non-significant impacts on it. It shows that the interaction of trust and security has a stronger influence on information adoption than that of the rest two interactions.

The theoretical reference provided in this research includes two aspects: On one hand, this paper focuses on virtual communities, and it analyzes users' behaviors of interaction participation and information adoption. The majority of the relevant literature only illustrates one kind of behavior of users in virtual communities (interactive participation or information adoption), and it has deficiency in studying in the two sorts of behaviors. This paper provides a new thought in studying interaction participation and information adoption of the users' behavior in virtual communities. On the other hand, this paper researches users' behaviors, focusing on the main effects and the interaction effects of the influencing factors, which is supported by the empirical study. In the previous study of users' behavior in virtual communities, it mainly uses the main effect for its explanation. This paper, by combining the main effect and the interaction effect, analyzes users' behavior, and contribute new methods in related researches.

In this paper, the empirical results indicate that the virtual community's managers should pay attention to different behaviors of users in the virtual community and 
they are influenced by many factors. In the process of their conducting architecture designs, function settings and system improvements in the virtual community, there is a need to adjust relationships between the different factors and to enforce the construction of the virtual community so as to support users' behaviors, and to promote the development of the virtual community.

Limitations of the study and future directions in this paper include: in the setting of variable there is a lack of consideration to information, information man and information environment. To open and diverse virtual communities, these three main elements are influenced by many factors. This paper only selects the most important one as a variable from the factors influencing the three main elements respectively. Meanwhile, in its measuring the variable, its measurement just reflects subjective adopted willingness of users in virtual communities. Therefore, in the future investigation, we could collect the data of users' real behavior in virtual communities (for example, access numbers, reply numbers, collection numbers, etc.,) to proceed objective verification. Besides, because different types of virtual communities will have different influences on information adoption, future research may focus on one type of virtual communities (such as a learning community, an interesting community, a transaction community, etc.,) to carry out a targeted study on information adoption.

\section{Acknowledgments}

This work was supported by Grants from Chongqing University of Posts and Telecommunications Undergraduates' Scientific Research Training Program in 2015, "Information searching and knowledge sharing behavior of network users".

\section{References}

[1] C. M. Chiu, M. H. Hsu and E. T. G. Wang, "Understanding Knowledge Sharing in Virtual Communities: An Integration of Social Capital and Social Cognitive Theories", Decision Support Systems, no. 42, (2006), pp. 1872-1887.

[2] M. H. Hsu, T. L. Ju, C. H. Yen and C. M. Chang, "Knowledge Sharing Behavior in Virtual Communities: The Relationship between Trust, Self-Efficacy, and Outcome Expectations", International Journal of Human-Computer Studies, vol. 65, no. 2, (2007), pp. 153-169.

[3] X. Jiang, "The Review of the Influencing Factors of Virtual Community Information Sharing Behavior", Research on Library Science, no. 10, (2014), pp. 18-24.

[4] A. Schröder and K. Hölzle, "Virtual Communities for Innovation: Influence Factors and Impact on Company Innovation", Creativity \& Innovation Management, vol. 19, no. 3, (2010), pp. 257-268.

[5] W. S. Yoo, K. S. Suh and M. B. Lee, "Exploring the Factors Enhancing Member Participation in Virtual Communities", Journal of Global Information Management, vol. 10, no. 3, (2002), pp. 551-570.

[6] C. M. K. Cheung, M. K. O. Lee and N. Rabjohn, "The Impact of Electronic Word-of-Mouth:The Adoption of Online Opinions in Online Customer Communities", Internet Research, vol. 18, no. 3, (2008), pp. 229-247.

[7] X. Y. Song and P. Wang, "Research on Concept and Effective Factors of Information Adoption Behavior", Information Science, vol. 28, no. 5, (2010), pp. 760-767.

[8] Y. F. Yang, H. C. Yeh and W. K. Wong, "The Influence of Social Interaction on Meaning Construction in a Virtual Community", British Journal of Educational Technology, vol. 41, no. 2, (2010), pp. 287-306.

[9] Y. C. Shen, C. Y. Huang, C. H. Chu and H. C. Liao, "virtual community loyalty: an interpersonalinteraction perspective", International Journal of Electronic Commerce, vol. 15, no. 1, (2010), pp. 49-74.

[10] R. Cheung, "The Influence of Electronic Word-of-Mouth on Information Adoption in Online Customer Communities", Global Economic Review, vol. 43, no. 1, (2014), pp.42-57.

[11] A. Nguyen and M. Western, "Socio-Structural Correlates of Online News and Information Adoption/Use: Implications for the Digital Divide", Journal of Sociology, vol. 43, no. 2, (2007), pp. 167-185.

[12] K. Y. Lee and S. B. Yang, "The Role of Online Product Reviews on Information Adoption of New Product Development Professionals", Internet Research, vol. 25, no. 3, (2015), pp. 435-452.

[13] K. Y. Yang, "Research on Information Ecosystem Construction about E-business", Information Science, vol. 32, no. 3, (2014), pp. 37-42.

[14] B. A. Nardi and V. L. O'day, Editor, "Information Ecologies: Using Technology with Heart”, MA: MIT Press, Cambridge, (1999).

[15] X. C. Fan, "An Empirical Study on Influencing Factors of Mobile Library User Behavior: Based on 
Information Ecology Perspective", Research on Library Science, no. 14, (2015), pp. 85-93.

[16] X. S. Chen and J. R. Yuan, "Research of the Information System Elements of Enterprise Information Resource Ecological System”, Technology Economics, no. 7, (2002), pp. 21-22.

[17] S. Chen, "Information Ecological Imbalance and Balance", Information and Documentation Services, no. 4, (2002), pp. 12-13.

[18] L. Q. Jiang, "Information Ecology and Social Sustainable Development", Beijing Library Press, Beijing, (2003).

[19] X. W. Wang and D. Liu, "Research of the Elements and Evaluation Index Construction of Enterprise Information Ecological System", Library and Information Service, vol. 54, no. 16, (2010), pp. 22-25.

[20] M. D. Li, "The Analysis of Information Ecology System”, Journal of Information, vol. 17, no. 4, (1998), pp. 3-5.

[21] X. W. Wang, M. Q. Yang and Y. F. Xing, "Construction and Empirical Research of the Ecological Evaluation Index for WAP Portal: Analysis Based on Information Ecology Perspective", Information studies: Theory \& Application, vol. 38, no. 6, (2015), pp. 14-18.

[22] T. Mayayise and O. I. Olusegun, "E-Commerce Assurance Models and Trustworthiness Issues: An Empirical Study", Journal of Information Management \& Computer Security, vol. 22, no. 1, (2014), pp. 76-96.

[23] J. Zhang and R. A. Cohen, "Framework for Trust Modeling in Multiagent Electronic Marketplaces with Buying Advisors to Consider Varying Seller Behavior and the Limiting of seller bids", ACM Trans on Intelligent Systems and Technology, vol. 4, no. 2, (2013), pp. 1-33.

[24] Institute of Information Sciences of Shanghai Academy of Social Sciences, Editor, "Information Security Dictionary", Shanghai Lexicographical Publishing House, Shanghai, (2013).

[25] D. Gefen, E. Karahanna and D. Straub, "Trust and TAM in Online Shopping: An Integrated Model", MIS Quarterly, vol. 27, no. 1, (2003), pp. 51-90.

[26] S. X. Luo, "Research of WOM Communication Effect on Purchase Decision: the Case of College Students", Zhejiang University Dissertation, Hangzhou, (2007).

[27] X. W. Wang, M. Q. Yang, W. X. Zhang and Y. Guo, "Evaluation of the Ecology of the Enterprise Information Portal: Analysis Based on the Perspective of Customer Experience", Library and Information Service, vol. 58, no. 4, (2014), pp. 46-52.

[28] Y. F. Lu, "Research on the Model of Interactive Communication in Virtual Community Effecting on Online Purchase Intention", Zhejiang University Dissertation, Hangzhou, (2005).

[29] X. P. Fan, "Virtual Communities Member's Participating Motive: An Empirical Study on Non-trade Virtual Community in China", Journal of Industrial Engineering and Engineering Management, vol. 23, no. 1, (2009), pp. 1-6.

[30] X. Y. Song, "Research on Construction and Application of User Information Adoption Behavior Model", Jilin University Dissertation, Changchun, (2010).

[31] J. F. Hair, R. E. Anderson, R. L. Tatham and W. C. Black, "Multivariate Data Analysis", Prentice Hall, New Jersey, (1998).

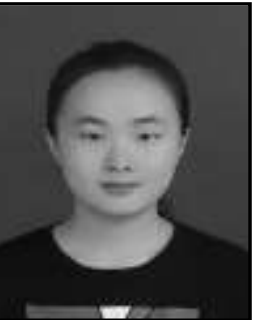

\section{Authors}

Yi Peng, she is an Undergraduate in the School of Economics and Management, Chongqing University of Posts and Telecommunications, China. Her research interests are in the fields of technological innovation and knowledge management.

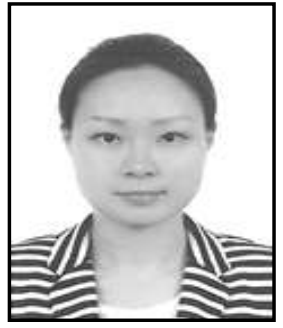

Jing Chen, she is a Lecturer in the School of Economics and Management, Chongqing University of Posts and Telecommunications, China. She received her master degree in the Management School of the University of York in United Kingdom. Her research interests are in the fields of maketing management and bilingual teaching. 


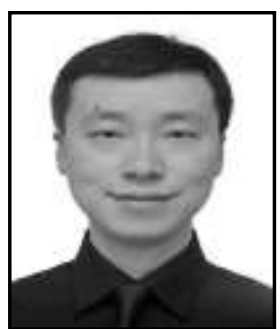

Yi Li, he is a Professor in the School of Economics and Management, Chongqing University of Posts and Telecommunications, China. He received his Ph.D. in Management from Chongqing University, China. His research interests are in the fields of technological innovation and knowledge management. 